\title{
Angiotensin II and hypoxia induce autophagy in cardiomyocytes via activating specific protein kinase $\mathbf{C}$ subtypes
}

\author{
Rong Xiao ${ }^{1}$, Hai-Chun Zhao ${ }^{1}$, Tian-Tian Yan ${ }^{1}$, Qiong Zhang ${ }^{2}$, Yue-Sheng Huang ${ }^{3}$ \\ ${ }^{1}$ Burn Center of PLA, No. 990 Hospital of PLA, Zhumadian, China; ${ }^{2}$ Institute of Burn Research, State Key Laboratory of Trauma, Burns and \\ Combined Injury, Southwest Hospital, The Third Military Medical University, Chongqing, China; ${ }^{3}$ Department of Wound Repair, Institute of \\ Wound Repair, Shenzhen People's Hospital, the First Affiliated Hospital of Southern University of Science and Technology, and the Second Clinical \\ Medical College of Jinan University, Shenzhen, China \\ Contributions: (I) Conception and design: YS Huang, R Xiao; (II) Administrative support: HC Zhao, TT Yan, Q Zhang; (III) Provision of study \\ materials or patients: TT Yan, Q Zhang; (IV) Collection and assembly of data: R Xiao, HC Zhao; (V) Data analysis and interpretation: R Xiao, YS \\ Huang; (VI) Manuscript writing: All authors; (VII) Final approval of manuscript: All authors. \\ Correspondence to: Yue-sheng Huang, PhD, MD. Department of Wound Repair, Institute of Wound Repair, Shenzhen People's Hospital, the First \\ Affiliated Hospital of Southern University of Science and Technology, and the Second Clinical Medical College of Jinan University, Shenzhen \\ 518020, China. Email: yshuangtmmu@163.com.
}

Background: The purpose of this study was to explore the role of protein kinase C (PKC) isozymes and reactive oxygen species (ROS) in hypoxia and angiotensin (Ang) II-induced autophagy.

Methods: Primary cardiomyocytes were isolated from Sprague-Dawley (SD) neonatal rats and cultured in hypoxia and/or Ang II conditions. Dihydroethidium fluorescence staining was used to detect the content of ROS. Cardiomyocyte autophagy was determined using Monodansylcadaverine fluorescence staining and Western blot. We also inhibited ROS production to explore the relationship between ROS and autophagy. ELISA was used to detect the contents of PKC $\delta$ and PKC $\varepsilon$. After inhibition of PKC $\delta$ activation and PKC $\varepsilon$ expression by lentiviral siRNA, ROS content and autophagy of cultured cardiomyocytes were detected.

Results: Hypoxia and Ang II stimulation increased autophagy in cardiomyocytes, accompanied by increased intracellular ROS production. Inhibiting ROS following hypoxia or Ang II stimulation significantly suppressed autophagy in comparison with hypoxia or Ang II stimulation group. Inhibiting PKC $\delta$ significantly reduced ROS production and autophagy activity following hypoxia or accompanied with Ang II stimulation except Ang II stimulation alone. Knockdown of PKC $\varepsilon$ notably decreased ROS production and autophagy in response to Ang II alone and in combination with hypoxia rather than hypoxia alone.

Conclusions: Both hypoxia and Ang II stimulation can induce autophagy in cardiomyocytes through increasing intracellular ROS. However, hypoxia and Ang II stimulation induced myocardial autophagy via $\mathrm{PKC} \delta$ and $\mathrm{PKC} \varepsilon$, respectively.

Keywords: Autophagy; cardiomyocytes; hypoxia/ischemia injury; angiotensin II (Ang II); protein kinase C (PKC)

Submitted Oct 26, 2020. Accepted for publication May 17, 2021.

doi: $10.21037 / \mathrm{cdt}-20-883$

View this article at: http://dx.doi.org/10.21037/cdt-20-883

\section{Introduction}

Autophagy maintains the physiological functions of cells by degrading some long-lived proteins and damaged organelles to provide amino acids and fatty acids for recycling. Autophagy improves the self-adaptability of cells under some pathological conditions, especially in the absence of nutrients (1). Cellular autophagy is a procedural dynamic process. First, a double membrane vesicle structure is formed inside the cell to envelop the materials to be digested. Then, the outer membrane and lysosomes fuse into autophagasomes, whose contents are digested and degraded to recycle macromolecular substances (2). In the process of 
autophagy, the microtubule associated protein 1 light chain 3 (LC3) is constantly transformed from type I to type II (3). Therefore, the ratio of LC3 II to LC3 I is an important indicator of autophagy. At present, the role of autophagy in myocardial ischemia/reperfusion injury has not been clearly stated (4). It was reported that autophagy can suppress apoptosis and activate anti-injury stress in pigs with chronic myocardial ischemia (5). Autophagy also plays a protective role in HL-1 cells with ischemia/reperfusion injury (6). However, another report showed that blocking autophagy using 3-methyladenine significantly induced a decreased death rate in $\mathrm{H} 9 \mathrm{c} 2$ cells in glucose free medium (7). Moreover, Urocortin can inhibit autophagic cell death induced by Beclin-1 in myocardial ischemia/reperfusion injury (8). Matsui et al. proposed that autophagy played a protective role in the myocardial ischemia phase and may be harmful in the reperfusion phase, with each phase depending on different cell signaling pathways (9).

Under the stress condition of severe burns, cardiac perfusion is significantly reduced very early post-burn (10), which is likely attributed to the acute activation of the local cardiac renin angiotensin system (RAS) (11). The cardiac RAS can react rapidly under stress and result in various paracrine or autocrine effects, including positive inotropic action, cardiac hypertrophy, mechanical stretch, cardiovascular remodeling, and apoptosis (12). Although its mechanism is not clear, the clinical application of angiotensin-converting enzyme inhibitors and angiotensin receptor blockers has proved that cardiac RAS plays certain roles in maintaining cell homeostasis, inhibiting cell proliferation and regulating myocardial stress (12). It has been confirmed that all active components of the RAS exist in cardiac tissues. Specifically, it showed that cardiac mast cells secrete renin as a result of degranulation, and then effectively produce angiotensin (Ang) II, which causes stimulation of sympathetic nerve endings, release of norepinephrine and subsequent arrhythmia $(13,14)$. Renin secreted from mast cells is the hub of local RAS activation (13). Porrello et al. $(15,16)$ demonstrated that Ang II can enhance autophagy through its type I receptor (AT1) and antagonize it through its type II receptor (AT2). Cardiac RAS and autophagy are two major systems of cardiac stress response, and their interaction has attracted extensive attention of scholars (17). However, it remains unknown how Ang II activates autophagy. Reactive oxygen species (ROS) and NADPH oxidase play important roles in Ang II-induced apoptosis (18), and ROS can also activate autophagy (19). Therefore, we explored if ROS participate in the cell signaling pathway by which Ang II induces autophagy in myocardial ischemia/reperfusion injury.

Protein kinase $\mathrm{C}(\mathrm{PKC})$ is an important signal transduction molecule that is involved in most cell physiological functions $(20,21)$. PKC is divided into 10 subtypes according to its structures and functions. In myocardial ischemia/reperfusion injury, PKC $\varepsilon$ is activated and confers protection during the ischemia period, while PKC $\delta$ is harmful during the reperfusion period (22). Although PKC $\varepsilon$ and PKC $\delta$ belong to the same group, they often have opposing physiological effects (23). In recent years, researchers have found that PKC also participates in the regulation of autophagy (24-30). However, it is not clear what role PKC plays in autophagy.

We preliminarily explored the roles of Ang II and ROS in the induction and activation of autophagy in cardiomyocytes in previous study (31). This study was performed to further explore the regulating factors of autophagy under hypoxia and/or Ang II stimulation in cardiomyocytes.

We present the study in accordance with the ARRIVE reporting checklist (available at http://dx.doi.org/10.21037/ cdt-20-883).

\section{Methods}

The protocols concerning animal experiments were reviewed and approved by the Animal Experimental Ethics Committee of the Third Military Medical University, Chongqing, China (SYXK-CQ-20070002), in compliance with Chinese national or institutional guidelines for the care and use of animals.

\section{Reagents}

DMEM/F12 medium (Hyclone, USA); high quality fetal bovine serum (FBS, Gibico, USA); 5-bromo-2-uridine (BrdU, Sigma, USA); pancreatin (Amresco, USA); recombinant angiotensin II (Peprotech, USA); Rottlerin (Enzo, USA). PMA (Sigma, USA); Diazoxide (Sigma, USA); EAVSLKPT (PKC $\varepsilon$ translocation inhibitor peptide, Calbiochem, USA); DPI (diphenylene iodonium, sigma, USA).

\section{Culture preparation and purification}

A total of 10-20 suckling SD rats on 1-3 days after birth were soaked in alcohol and sterilized to the operating panel with high temperature disinfection. Fix the suckling mice, cut off the neck, cut off the chest wall, expose the heart, and take out the lower $1 / 3$ of the ventricular muscle. Wash 
it three times in ice PBS $(0.01 \mathrm{M})$, remove the blood clot, and cut off the connective tissues. The myocardial tissues were cut to $1 \mathrm{~mm}^{3}$ with ophthalmic scissors, and then transferred into a digestion bottle with a volume of about $50 \mathrm{~mL} .0 .1 \%$ trypsin $(20-40 \mathrm{~mL})$ was added, stirred with a magnetic stirrer (100-200 rpm/min), and digested at $37{ }^{\circ} \mathrm{C}$ for $10 \mathrm{~min}$. The supernatant was digested for the first time. The remaining myocardial tissue was digested with trypsin. Repeated digestion was performed 8-10 times with 5-8 min each time until the tissue was completely digested. The supernatant was collected and the residual trypsin activity was inactivated in DMEM/F12 medium containing 10\% FBS. The precipitates were collected by centrifugation for $5 \mathrm{~min}$ (1,000 rpm/min). Add DMEM/F12 medium containing 10\% FBS and 0.01M BrdU, gently blow until well mixed. All myocardial cell suspensions were filtered with 200 mesh filter and transferred to culture dish. Fibroblasts adhered to the wall after standing at $37^{\circ} \mathrm{C}$ for $1 \mathrm{~h}$. The transferred cell suspension was counted with disposable counting plate. Put the packed cells into the incubator and change the solution every other day. Stimulation was applied after 2-3 days.

\section{Cell culture and experimental treatment}

Ten healthy neonatal Sprague Dawley (SD) rats were provided by the laboratory animal center of Third Military Medical University. The rats were euthanized and hearts were collected for extracting purified myocardial cells. Cardiomyocytes cultured in normal oxygen were used as the control group. Cardiomyocytes in the hypoxia were treated with a low oxygen mixture containing $94 \% \mathrm{~N}_{2}, 5 \% \mathrm{CO}_{2}$ and $1 \% \mathrm{O}_{2}$ for $30 \mathrm{~min}, 1 \mathrm{~h}$, or $3 \mathrm{~h}$ (32). Cardiomyocytes in the Ang II group were treated with $1 \mu \mathrm{M}$ Ang II (PeproTech, USA) for $30 \mathrm{~min}$, $1 \mathrm{~h}$, or $3 \mathrm{~h}$. For hypoxia and Ang II stimulation, $1 \mu \mathrm{M}$ Ang II was added to cells that were cultured in low oxygen mixture. For cells treated with $1 \mu \mathrm{M}$ Rottlerin (Enzo, USA), 0.175 $\mu \mathrm{M}$ PMA (Sigma, USA), $100 \mu \mathrm{M}$ Diazoxide (Sigma, USA), $200 \mu$ M EAVSLKPT (a PKC $\varepsilon$ translocation inhibitor peptide, Calbiochem, USA), $5 \mu$ M DPI (Diphenylene iodonium, Sigma, USA), and the lentivirus siRNA interference, the hypoxia and/or Ang II stimulating duration was 3 h. PMA and Diazoxide were used as PKC activators in PKC inhibition experiments, whereas DPI was used as ROS inhibitor.

\section{PKC $\varepsilon$ siRNA transfection}

The PKC $\varepsilon$ RNA interfering recombinant lentivirus was provided by Beijing Dingguo Biotechnology Co., Ltd
(Beijing, China). The lentiviruses containing three siRNA fragments (10: GGTAGTGTTCAATGGCCTT/1285: G C T C A A G G TA A G G A T G A / 1291 : GGGTAAGGATGAAGTCTAT) for PKC $\varepsilon$ mRNA sequences (Rattus norvegicus) were respectively mixed with the cultured cardiomyocytes in good growth state. In brief, 3,000-5,000 cells were inoculated in a 96-well culture plate with $90 \mu \mathrm{L}$ culture medium the day before the experiment. The degree of cell fusion during viral infection was maintained at 30-50\%. The infection experiment was divided into two groups according to the different infection conditions. For the first group, the virus was added directly to the normal medium. For the second group, $8 \mu \mathrm{g} / \mathrm{mL}$ Polybrene, a virus infection enhancer, was added to the culture medium. There were three different gradients of moieties of infection (MOI) in each infection group, including 100, 10, and 1. The culture plates were gently flapped in the horizontal direction to thoroughly mix the medium and reagents. After 8-12 h, the supernatants were discarded and the medium was changed. After 3-4 days of infection, fluorescence was observed and PKC $\varepsilon$ knockdown efficiency was assessed using Western blot analysis.

\section{DHE fluorescence staining}

DHE is a rapid and simple method for ROS detection in tissues or cultured living cells (33). Cardiomyocytes were cultured on glass coverslips. After treatment, the cells were washed with phosphate buffered saline (PBS) for three times with $3 \mathrm{~min}$ each time. All of the following steps were performed under the condition of avoiding light. DHE (Dihydroethidium, Beyotime, China) was dissolved in dimethyl sulfoxide (DMSO) for storage and diluted to $10 \mu \mathrm{M}$ with PBS for use. Adherent cells were incubated with DHE at $37^{\circ} \mathrm{C}$ for $30 \mathrm{~min}$, and then were rinsed with PBS for three times with 5 min each time. The cells were sealed with $70 \%$ glycerol for fluorescence observation. Under fluorescence microscopy, blue or green light (excitation wavelength: 370-420 nm) was used to generate red fluorescence while DHE was oxidized and dehydrogenated by ROS in cardiomyocytes. Cells in each group were randomly photographed at high power field (400x), 20 cells were selected, and the average fluorescence intensity of each cell was analyzed using ImageJ software.

\section{MDC fluorescent staining}

MDC serves as a specific indicator of autophagy (34-36). Similar to the DHE fluorescence staining 
procedure, cardiomyocytes were cultured on glass coverslips. After treatment, the cells were washed with PBS for three times with 3 min each time. The staining steps were performed under the condition of avoiding light. MDC (Monodansylcadaverine, Sigma, USA) was also dissolved in DMSO for storage, and its working concentration was $50 \mu \mathrm{M}$ dissolved in PBS. Adherent cells were incubated with $\mathrm{MDC}$ at $37{ }^{\circ} \mathrm{C}$ for $30 \mathrm{~min}$ and then washed with PBS. The cells were sealed with $70 \%$ glycerol. MDC combined with acidic autophagic vesicles in cardiomyocytes and presented as green fluorescence under fluorescence microscopy, which visually displayed the amount of autophagic vesicles. Cells in each group were randomly photographed at high power field (400x). Ten cells were selected and the average fluorescence intensity of each cell was analyzed using ImageJ software.

\section{Western blot analysis}

The total protein was extracted from cells with cold RIPA buffer (Beyotime Institute of Biotechnology, Shanghai, China). SDS-PAGE was performed with $30 \mu \mathrm{g}$ of total protein to separate protein. The proteins were transferred onto nitro fiber membrane. GAPDH was used as a loading control. Membrane was incubated with Beclin-1 polyclonal antibody (1:1,000; Cell Signaling, USA), LC3b polyclonal antibody (1:1,000; Cell Signaling, USA) and HRP-labeled rabbit anti-rat GAPDH antibody (1:5,000; Sigma, USA) overnight at $4{ }^{\circ} \mathrm{C}$. After washing, the membrane was incubated at room temperature for $1 \mathrm{~h}$ with anti-rabbit HRP-labeled secondary antibody solution (1:5,000; Santa Cruz, USA). After washing, the membrane was incubated with an enhanced chemiluminescence substrate (Amersham Pharmacia, USA) for 1-5 min to visualize the bands. The relative density of the target proteins was obtained using QuantityOne image analysis software (Bio-Rad, USA).

\section{Enzyme-linked immunosorbent assay (ELISA)}

PKC was detected using PKC $\varepsilon$ and PKC $\delta$ ELISA kits (Uscn Life, USA) according to the manufacturer's instructions. Plates were detected at an absorbance of $450 \mathrm{~nm}$ (A450) using a Sunrise microplate reader. PKC $\varepsilon$ and $\mathrm{PKC} \delta$ were tested in quadruplicates in two independent ELISA measurements.

\section{Statistical analysis}

All data are presented as means \pm standard error of the mean (SEM). SPSS 23.0 (International Business Machines, Corp., Armonk, NY, USA) was used for statistical analysis and significance was evaluated using one-way ANOVA followed by the Student-Newman-Keuls (SNK) post-hoc test. Differences were considered statistically significant when $\mathrm{P}<0.05$.

\section{Results}

\section{Hypoxia and/or Ang II stimulation increased intracellular ROS content and autophagy in cardiomyocytes}

We treated cardiomyocytes with $1 \% \mathrm{O}_{2}$ (hypoxia) and/ or $1 \mu \mathrm{M}$ Ang II for $30 \mathrm{~min}, 1 \mathrm{~h}$ or $3 \mathrm{~h}$, and then the cells were stained with DHE or MDC. We found that the intracellular ROS content was significantly increased with increased treatment time (Figure 1). Furthermore, the results showed that the number of autophagic vesicles was significantly increased in the hypoxia and Ang II groups compared with the control group $(\mathrm{P}<0.05)$. Moreover, the autophagic activity was increased with treatment time $(\mathrm{P}<0.05)$ (Figure $2 A, B)$. We extracted total proteins from each group of cardiomyocytes to detect the ratio of LC3 II/LC3 I. The results also confirmed that after hypoxia and/or Ang II treatment, the autophagic activity of the cardiomyocytes was significantly increased with increased treatment time $(\mathrm{P}<0.05)$ (Figure $2 C, D)$. In this experiment, the MDC staining and autophagy marker protein Atg8/LC3 detection were performed on cardiomyocytes for $30 \mathrm{~min}$, $1 \mathrm{~h}$ and $3 \mathrm{~h}$. It was found that the process of autophagy was enhanced with the passage of time, which was manifested by the gradual increase of acidic autophagic vesicles and the gradual increase of the transformation of LC3I to LC3II.

\section{Changes in autophagy in cardiomyocytes after inbibiting ROS}

Cardiomyocytes pretreated with DPI were treated with $1 \%$ $\mathrm{O}_{2}$ for $3 \mathrm{~h}$ and/or $1 \mu \mathrm{M}$ Ang II for $1 \mathrm{~h}$. After DHE staining, fluorescence in the DPI group was significantly reduced, demonstrating the that DPI inhibits intracellular ROS production (Figure $3 A, B$ ). We further investigated the effect of DPI on autophagy in cardiomyocytes. The results showed that the MDC staining fluorescence and the number of autophagic vesicles in cardiomyocytes were significantly reduced in the DPI group in comparison with the control group (Figure 3C,D). Western blot analysis of LC3 expression was consistent with the results of MDC staining, which suggested 
A

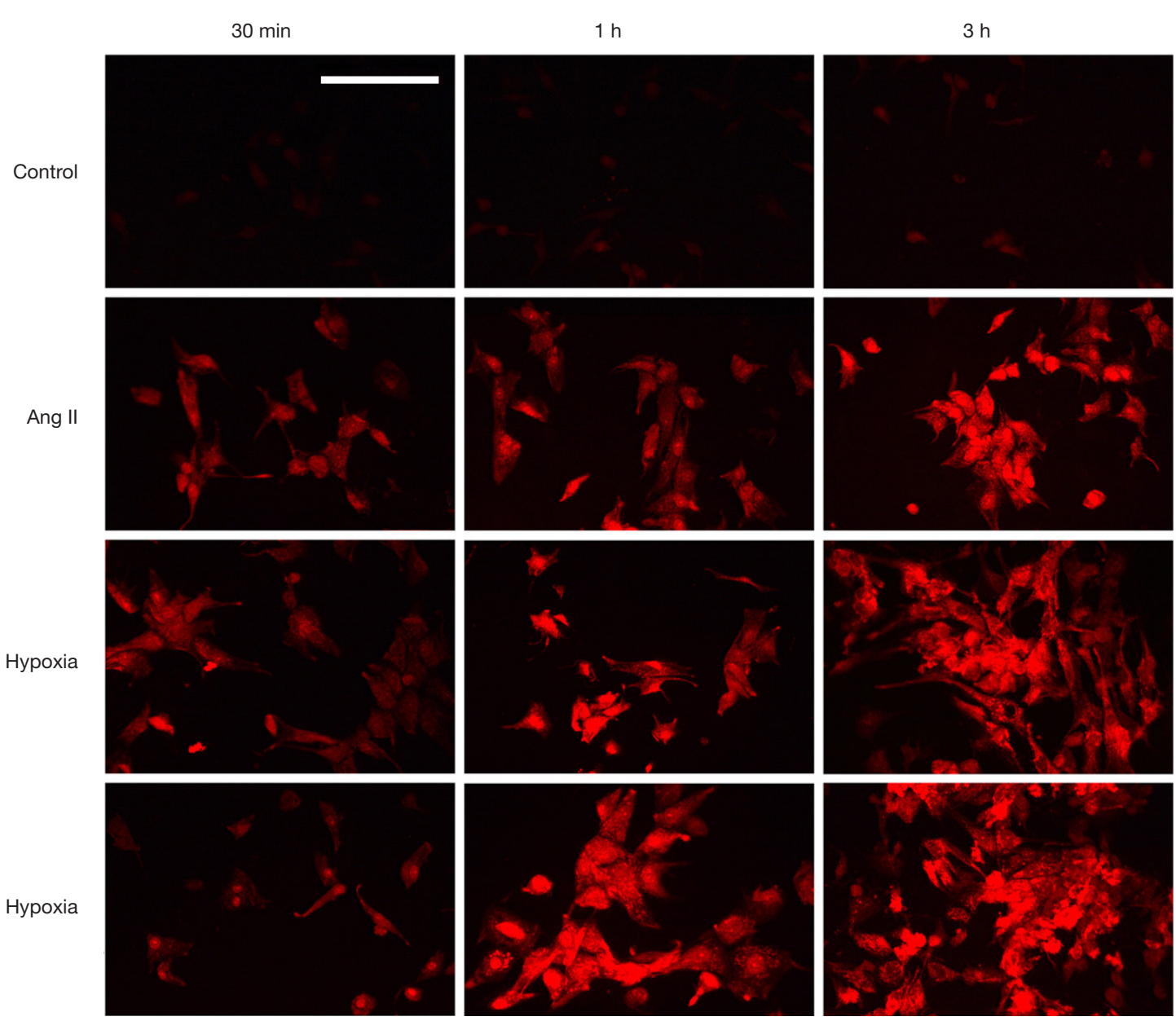

B

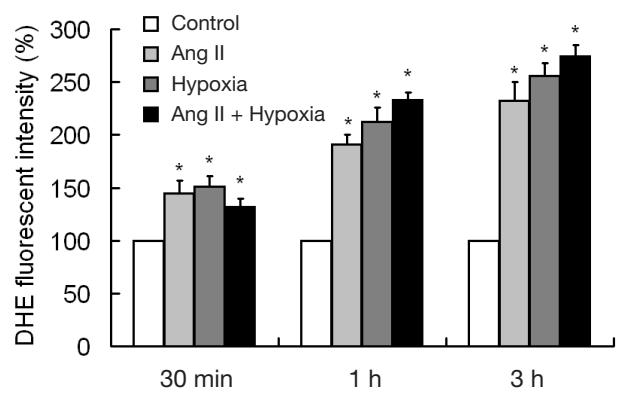

Figure 1 Increased ROS in cardiomyocytes under hypoxia and/or Ang II stimulation. After primary cultured cardiomyocytes were treated with $1 \% \mathrm{O} 2$ hypoxia and/or $1 \mu \mathrm{M}$ Ang II stimulation for $30 \mathrm{~min}, 1 \mathrm{~h}$, and $3 \mathrm{~h}$, cells were stained with DHE. (A) Representative images, scale bar: $100 \mu \mathrm{m}$. (B) Quantification of fluorescence intensity of the cells; $\mathrm{n}=5,{ }^{*} \mathrm{P}<0.05$, vs. control group.

that DPI inhibited autophagy in cardiomyocytes by inhibiting ROS (Figure 3E,F). To further explore the relationship between ROS and autophagy, we double stained the cardiomyocytes with DHE and MDC. The results showed that the intensities of red fluorescence and green fluorescence were significantly positively correlated in the same cell under hypoxia and/or Ang II stimulation, indicating an increase in cellular ROS content in autophagic vesicles (Figure 4). 
A

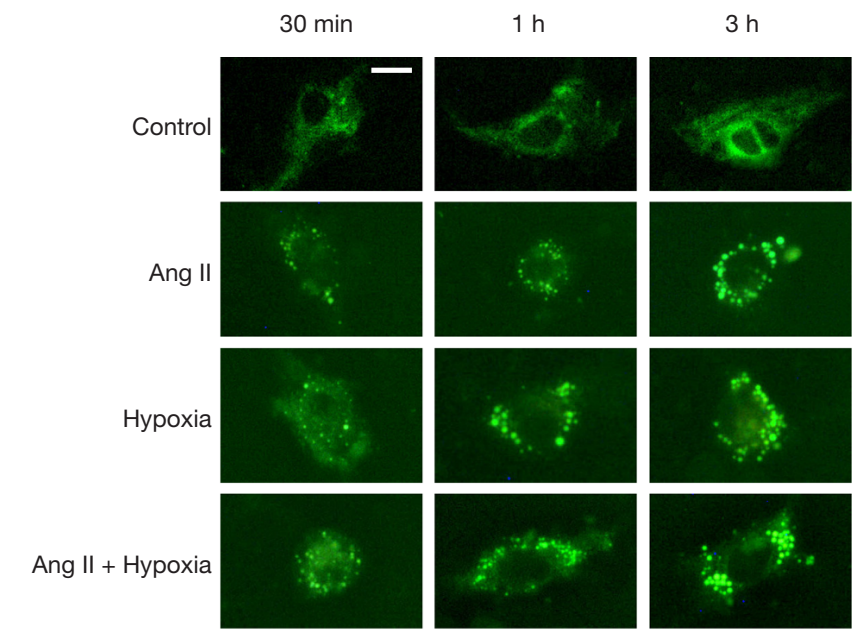

C

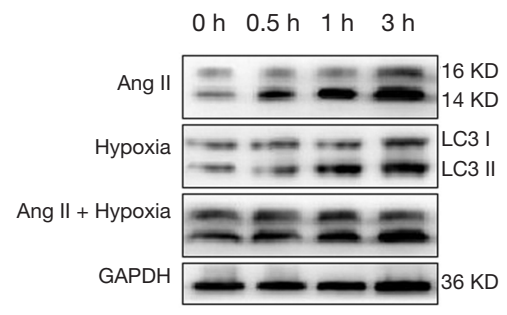

B

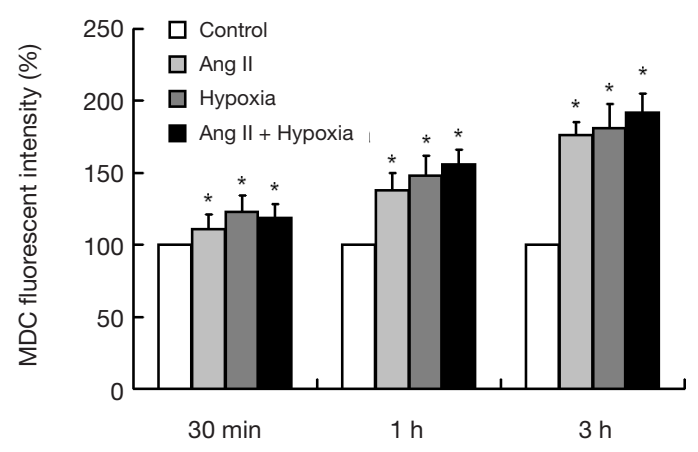

D

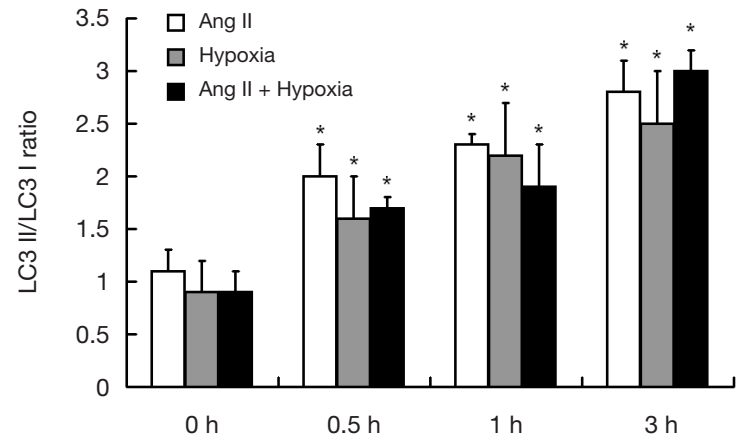

Figure 2 Increased autophagy in cardiomyocytes with hypoxia and/or Ang II stimulation. Primary cultured cardiomyocytes were treated with 1\% O2 hypoxia and/or $1 \mu \mathrm{M}$ Ang II stimulation for $30 \mathrm{~min}, 1 \mathrm{~h}$, and $3 \mathrm{~h}$, and then stained with MDC. (A) Representative images of single cardiomyocyte with MDC staining under fluorescence microscopy. Scale bar: $10 \mu \mathrm{m}$. (B) Quantification of fluorescence intensity of the cells; $\mathrm{n}=5,{ }^{*} \mathrm{P}<0.05$, vs. the control group. (C) Representative Western blot images of LC3 protein extracted from the cardiomyocytes of each group. (D) Quantitative comparison of LC3 II/LC3 I ratio. $\mathrm{n}=5,{ }^{*} \mathrm{P}<0.05$, vs. the $0 \mathrm{~h}$ group.

\section{Changes in PKC $\varepsilon$ and $P K C \delta$ in cardiomyocytes under stress condition}

We measured the levels of $\mathrm{PKC} \varepsilon$ and $\mathrm{PKC} \delta$ in cardiomyocytes after hypoxia treatment for $3 \mathrm{~h}$ and/or $1 \mu M$ Ang II stimulation for $1 \mathrm{~h}$ by ELISA. As shown in Figure $5 A, B, \mathrm{PKC} \varepsilon$ and $\mathrm{PKC} \delta$ levels were significantly upregulated under hypoxia and/or Ang II stimulation in comparison with control group $(\mathrm{P}<0.05)$. In addition, Rottlerin, the specific PKC $\delta$ inhibitor, had no effect on PKC $\delta$ expression. Similarly, the PKC $\varepsilon$ specific inhibitory peptide, EAVSLKPT, did not significantly affect PKC $\varepsilon$ expression, which suggested that the two inhibitors only inactivated at the protein level. Moreover, cardiomyocytes were infected with a lentivirus to knockdown PKC $\varepsilon$ expression. The blank control group contained no virus. The same batch of empty virus was added as the negative control group. Cells were treated with the same procedure as the lentivirus infection group (the siRNA group), including the infection enhancer Polybrene. ELISA results showed that the cellular content of PKC $\varepsilon$ in the siRNA group was significantly decreased regardless of normal culture or hypoxia and/or Ang II stimulation (Figure 5C).

\section{Effects of inbibition of PKC $\delta$ on autophagy in cardiomyocytes under bypoxia and/or Ang II stimulation}

To further clarify the role of PKC $\delta$ in myocardial autophagy under hypoxia and/or Ang II stimulation, we used Rottlerin to specifically inhibit PKC $\delta$ inactivation. DMSO was used 
A
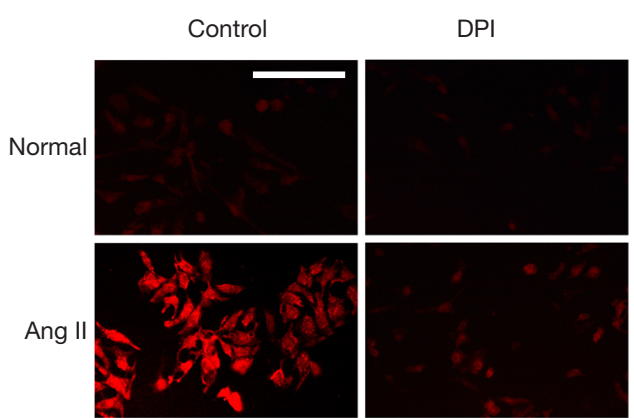

Hypoxia
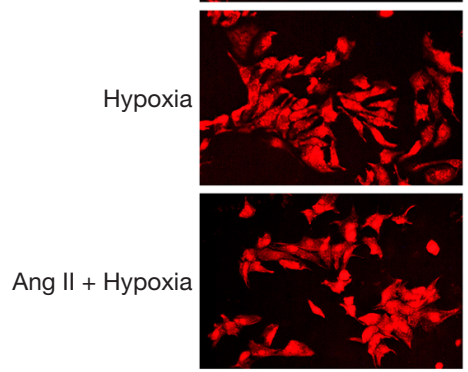

B

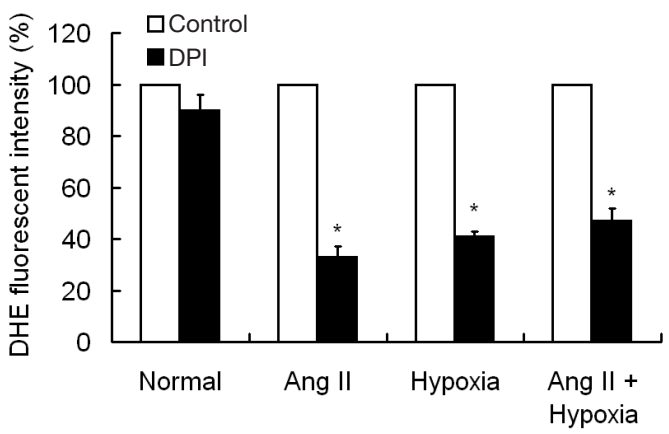

$E$

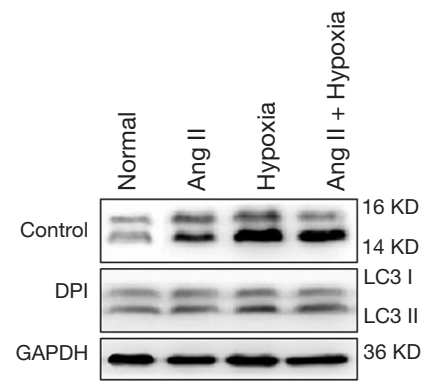

C

Control
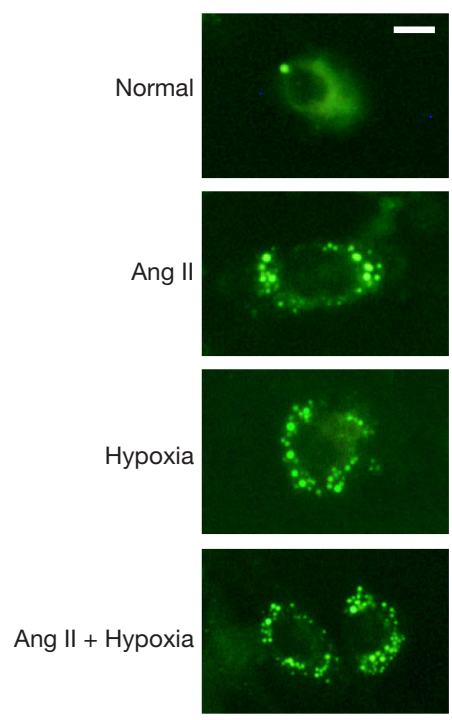

D
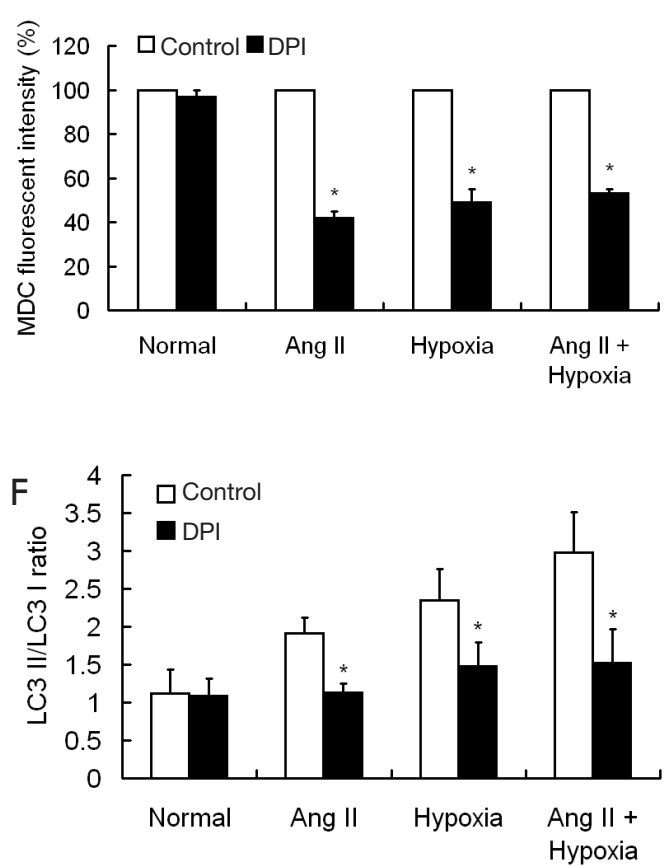

Figure 3 Inhibition of ROS reduced autophagy in cardiomyocytes. Primary cultured cardiomyocytes were pretreated with the ROS inhibitor DPI, and then treated with 1\% O2 hypoxia for $3 \mathrm{~h}$ and/or $1 \mu \mathrm{M}$ Ang II for $1 \mathrm{~h}$. (A) Representative images of live cells with DHE fluorescent staining. Scale bar: $100 \mu \mathrm{m}$. (B) Quantitative fluorescence intensity of DHE staining. $\mathrm{n}=5$, ${ }^{*} \mathrm{P}<0.05$, $v s$. the control group. (C) Representative images of primary cultured cardiomyocytes with MDC staining under fluorescence microscopy. Scale bar: $10 \mu \mathrm{m}$. (D) Quantitative fluorescence intensity of MDC staining. $\mathrm{n}=5$, ${ }^{*} \mathrm{P}<0.05$, vs. the control group. (E) Representative images of LC3 protein expression in each group. (F) Quantitative comparison of LC3 II/LC3 I ratio. $\mathrm{n}=5,{ }^{*} \mathrm{P}<0.05$, vs. the control group. 


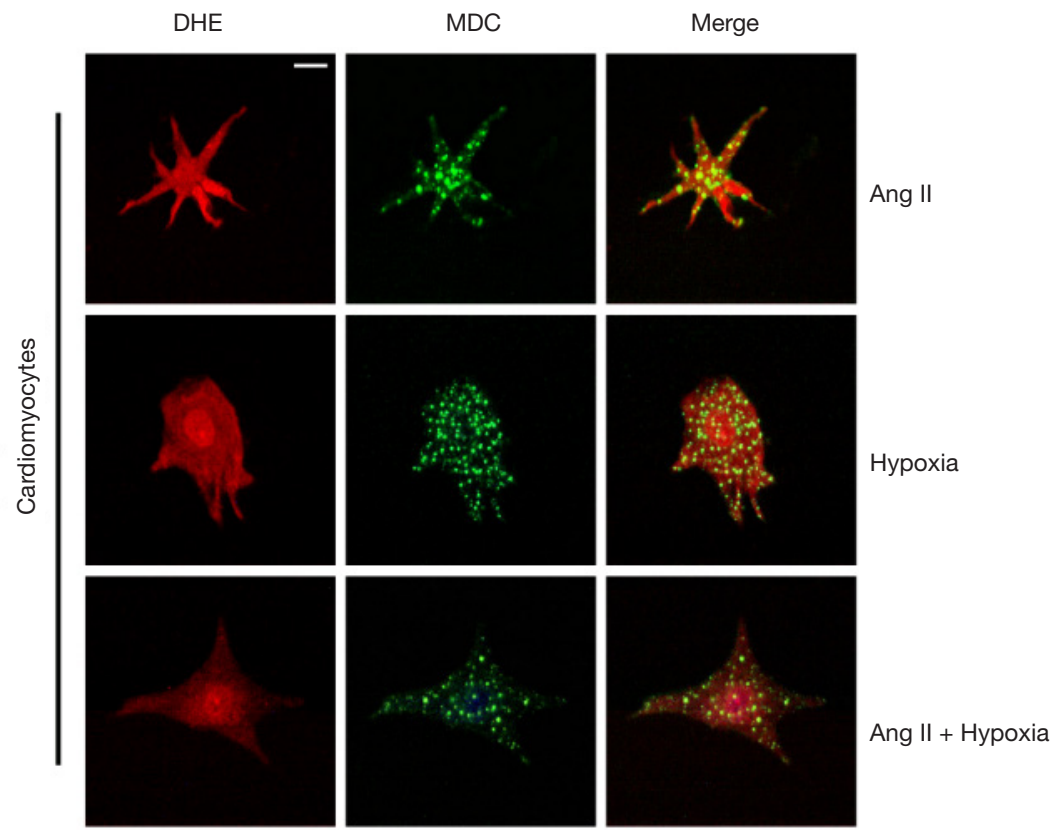

Figure 4 Representative images of DHE and MDC double staining in hypoxic and/or Ang II stimulated cardiomyocytes. Primary cultured cardiomyocytes were treated with 1\% O2 hypoxia for $3 \mathrm{~h}$ and/or $1 \mu \mathrm{M}$ Ang II stimulation for $1 \mathrm{~h}$. DHE and MDC were used to stain live cells. Scale bar: $10 \mu \mathrm{m}$.

as the control group. Rottlerin significantly reduced ROS production in the hypoxia group, as well as the hypoxia plus Ang II group $(\mathrm{P}<0.05)$. However, there was no significant difference in DHE fluorescence intensity between control group and Ang II group, suggesting that PKC $\delta$ was not involved in regulating Ang II-induced ROS production in cardiomyocytes (Figure 6A,B). The results of MDC staining showed that Rottlerin significantly reduced the number of autophagic vesicles in the hypoxia group, as well as inhibited autophagic activity of cardiomyocytes in the hypoxia plus Ang II group $(\mathrm{P}<0.05)$. However, under Ang II stimulation alone, there was no significant difference in fluorescence intensity of intracellular MDC compared with the control group $(\mathrm{P}>0.05)$. Those results suggested that PKC $\delta$ did not affect autophagy induced by Ang II (Figure 6C,D). Western blot analysis of LC3 was consistent with the results of MDC staining, showing that inhibition of PKC $\delta$ by Rottlerin only exerted an inhibitory effect on autophagy in cardiomyocytes under hypoxia rather than Ang II stimulation alone (Figure 6E,F).

\section{Effects of inbibition of PKC $\varepsilon$ on autophagy in cardiomyocytes under bypoxia and/or Ang II stimulation}

EAVSLKPT, a specific PKC $\varepsilon$ inhibitory peptide, was found to inhibit ROS production and autophagic activity in cardiomyocytes under Ang II stimulation (data not shown). We used RNA interference to knockdown PKC $\varepsilon$ expression in the cardiomyocytes. The blank control group contained no virus and the negative control group included the empty virus. We found that intracellular ROS production was significantly reduced following knockdown of PKC $\varepsilon$ under Ang II stimulation alone or mixed hypoxia treatment $(\mathrm{P}<0.05)$. However, compared with the control group, there was no significant difference in the fluorescence intensity of DHE in the cells under hypoxia alone $(\mathrm{P}>0.05)$. These results suggested that PKC $\varepsilon$ did not participate in the cell signal transduction pathway for ROS production induced by hypoxia alone, but played an important role in the ROS production pathway induced by Ang II (Figure 7). The results of MDC staining and Western blot analysis on LC3 both showed that autophagic activity in cardiomyocytes was significantly reduced in the lentivirus RNA interference group under Ang II stimulation or mixed hypoxia compared to the blank control group or the negative control group $(\mathrm{P}<0.05)$, while autophagic activity was not significantly different under the hypoxia condition alone $(\mathrm{P}>0.05)$ (Figure 8). These results suggested that PKC $\varepsilon$ is involved in Ang II-induced ROS production and autophagy in 
A

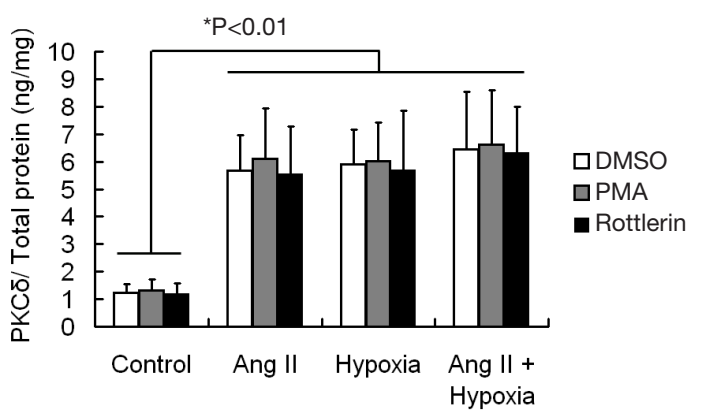

B

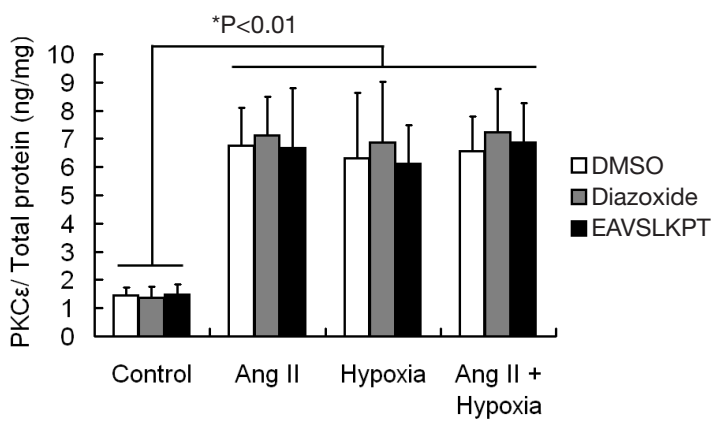

C

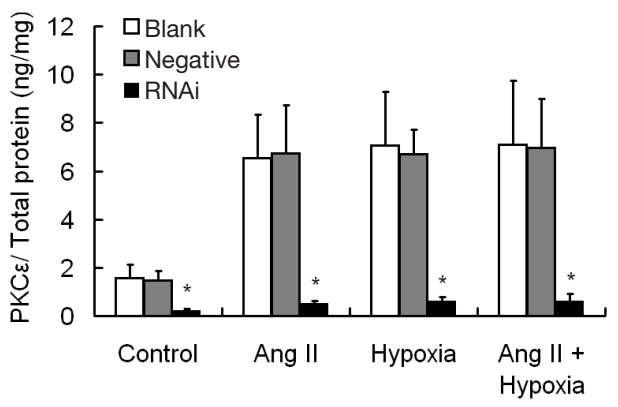

Figure 5 Changes in PKC $\delta$ and PKC $\varepsilon$ in cardiomyocytes under different conditions. PKC $\delta$ and PKC $\varepsilon$ in the primary cultured cardiomyocytes were quantified using ELISA after the cells were treated 1\% O2 hypoxia for $3 \mathrm{~h}$ and/or $1 \mu \mathrm{M}$ Ang II stimulation for $1 \mathrm{~h}$. PMA and Diazoxide were used as PKC activators in PKC inhibition experiments. (A,B) PKC $\delta$ and PKC $\varepsilon$ were both significantly upregulated under the hypoxia and/or Ang II stimulation in the cardiomyocytes, and the PKC PKC $\delta$ specific inhibitor, Rottlerin, did not affect protein expression of PKC. Similarly, PKC $\varepsilon$ specific inhibitor, EAVSLKPT, did not significantly affect protein expression of PKC $\varepsilon$. $\mathrm{n}=5,{ }^{*} \mathrm{P}<0.05$, vs. the control group. (C) Primary cultured cardiomyocytes were infected by a designed lentivirus that interferes with PKC $\varepsilon$ (the RNAi group). No virus was taken as a blank control group, and the negative virus was as the negative control group. ELISA results showed that the PKC $\varepsilon$ levels were significantly down-regulated in the cardiomyocytes regardless of culture condition. $\mathrm{n}=5,{ }^{*} \mathrm{P}<0.05$, $v s$. the blank control group or the negative control group.

cardiomyocytes via a positive regulatory role.

\section{Discussion}

Our previous study demonstrated that autophagic activity of cardiomyocytes was significantly increased in the early stage after severe burns, and autophagic cell death in the myocardium occurred $3 \mathrm{~h}$ after injury. Subsequently, as autophagic activity was further enhanced, myocardial autophagic cell death increased, accompanied by a gradual decline of cardiac function (31). There is no doubt that the increased autophagic activity of cardiomyocytes in the decompensation period of hypoxia is an important cause of myocardial damage in the early stage of severe burns. Another report also indicated that Ang II and ROS may be important signal transduction molecules that induce and activate autophagy in cardiomyocytes under the stress conditions of severe burns (31). It is known that the RAS in the heart is rapidly activated after burns, resulting in increased concentration of local Ang II in the myocardium, and that Ang II-mediated hypoxic/ischemic damage is also an important mechanism of early myocardial injury and decreased cardiac function (11). The discovery of Ang IIinduced autophagy was reported (16), but the underlying detailed mechanism has not been further investigated. Therefore, to better understand the mechanism of myocardial autophagy under the stress conditions of severe burns, we isolated cardiomyocytes from rats for primary culture and stimulated them with hypoxia and/or Ang II to have a pathophysiological environment in cardiomyocytes after burns. We further inhibited different cell signaling molecules to explore the relationships between Ang II, 
A

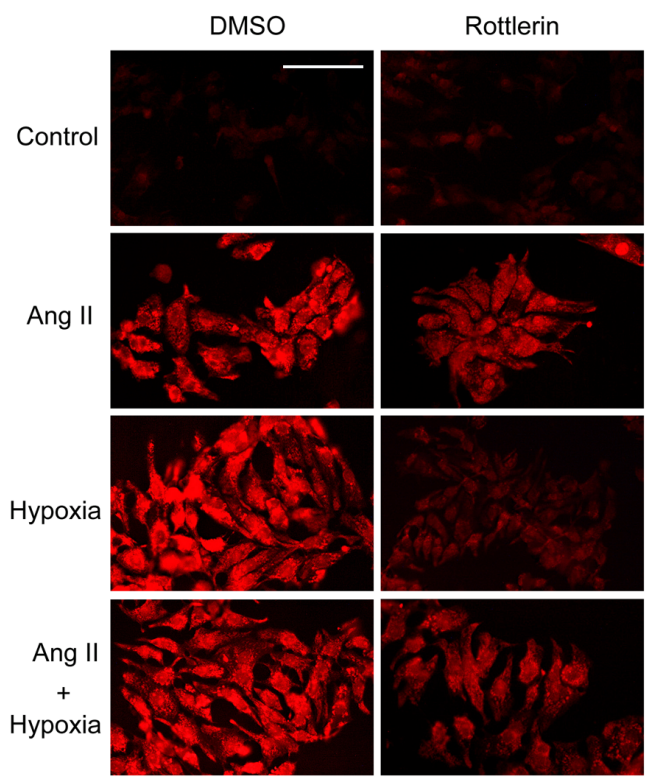

B

$\mathrm{E}$

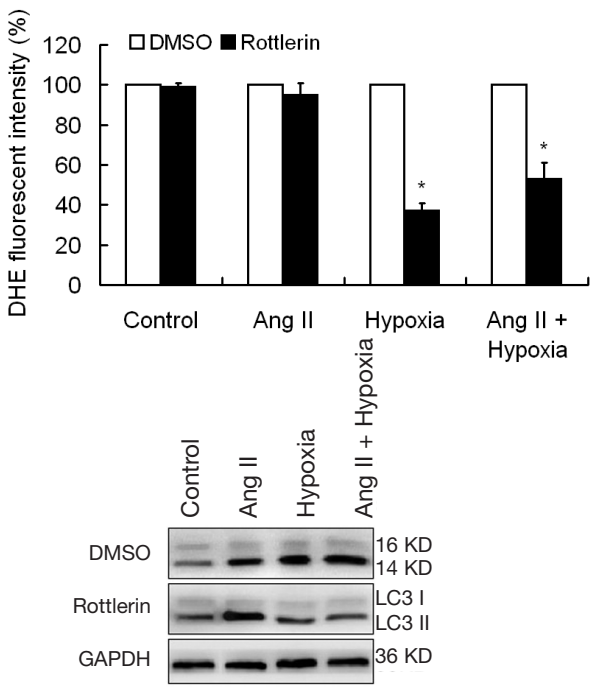

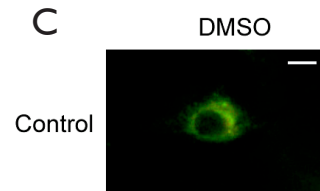
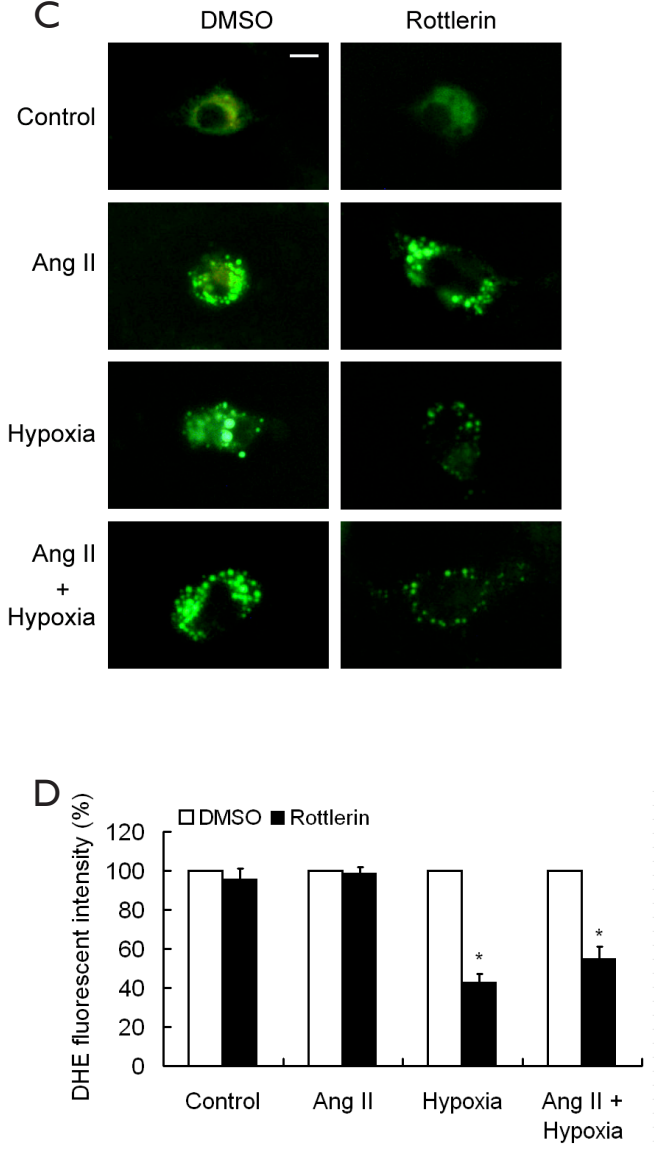

$\mathrm{F}$

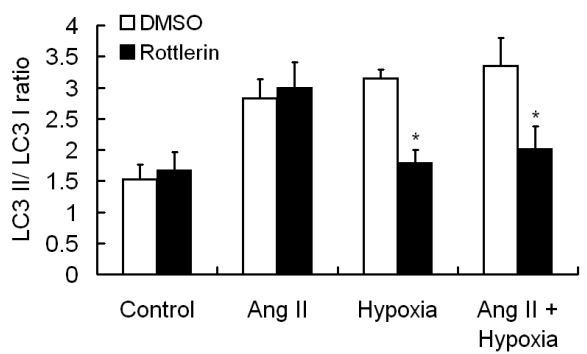

Figure 6 Effects of inhibition of PKC $\delta$ activity on autophagy in cardiomyocytes under hypoxia and/or Ang II stimulation. PKC $\delta$ activation in cardiomyocytes was inhibited Rottlerin. DMSO was used as control, Changes in intracellular ROS and autophagy activity were observed. (A) Representative images of DHE fluorescence staining of live cells. Scale bar: $100 \mu \mathrm{m}$. (B) Quantitative fluorescence intensity of DHE staining showed that Rottlerin significantly reduced ROS production in the hypoxia and hypoxia plus Ang II group. However, under Ang II stimulation alone, there was no significant difference in intracellular DHE fluorescence intensity compared with the DMSO group; $\mathrm{n}=5,{ }^{*} \mathrm{P}<0.05$, vs. the control (DMSO) group. (C) Representative images of primary cultured cardiomyocytes with MDC staining under fluorescence microscopy. Scale bar: $10 \mu \mathrm{m}$. (D) Quantitative fluorescence intensity of MDC staining showed that in the hypoxia treatment group, Rottlerin significantly reduced the number of autophagic vesicles and inhibited autophagic activity of cardiomyocytes in the hypoxia plus Ang II group. However, under the condition of Ang II stimulation alone, there was no significant difference in the intracellular MDC fluorescence intensity compared with the DMSO group. $\mathrm{n}=5,{ }^{*} \mathrm{P}<0.05$, vs. the control (DMSO) group. (E) Representative images of LC3 protein expression in each group. (F) Quantitative comparison of LC3 II/LC3 I ratio confirmed that Rottlerin inhibited PKC $\delta$ activity only under hypoxia condition, and not under Ang II stimulation alone. $\mathrm{n}=5$, ${ }^{*} \mathrm{P}<0.05$, vs. the control (DMSO) group. 
A

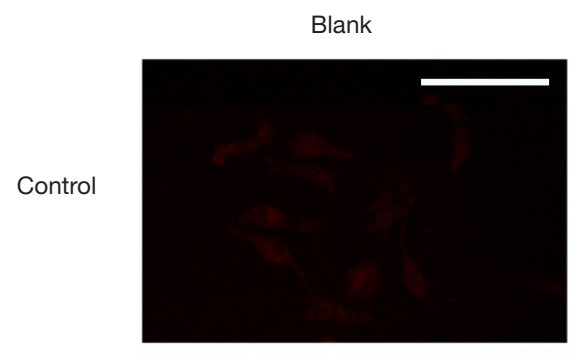

Ang II
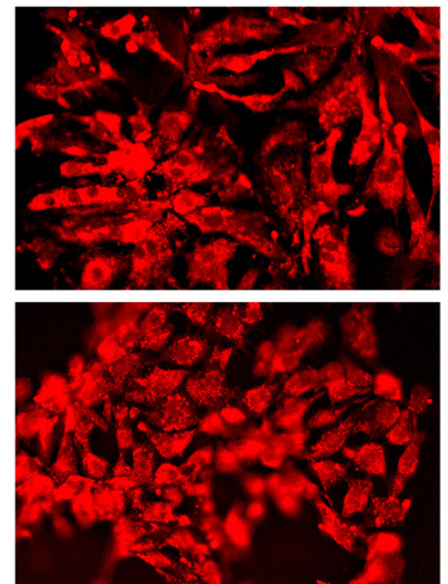

Ang II + Hypoxia

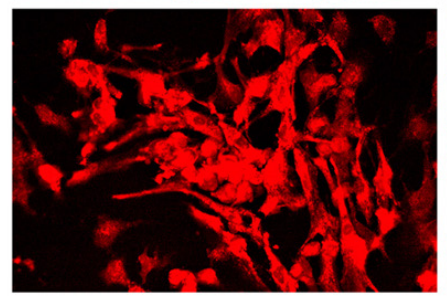

Negative
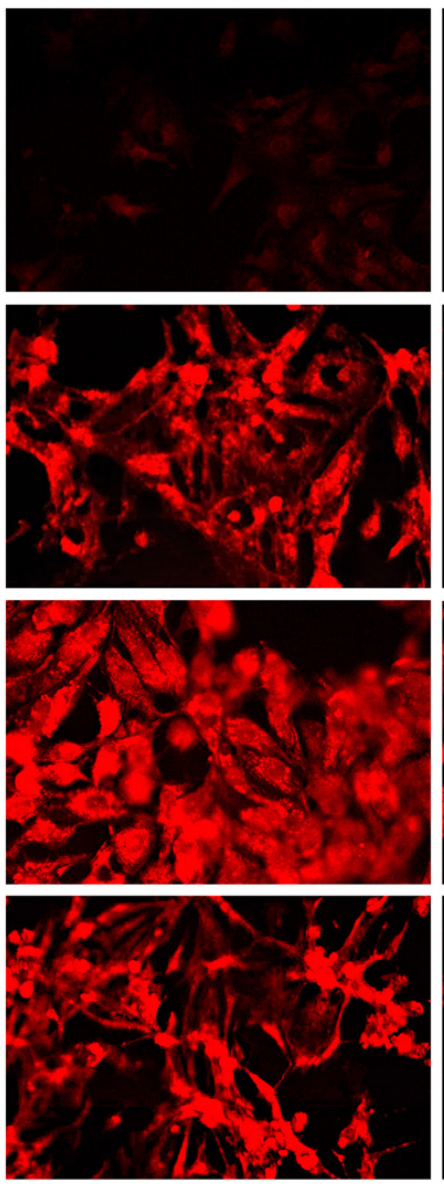

RNAi
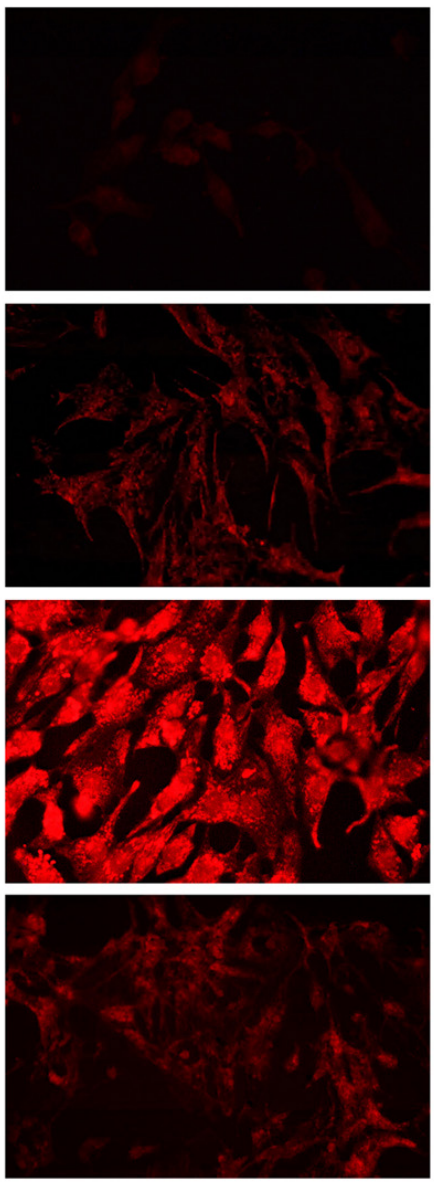

B

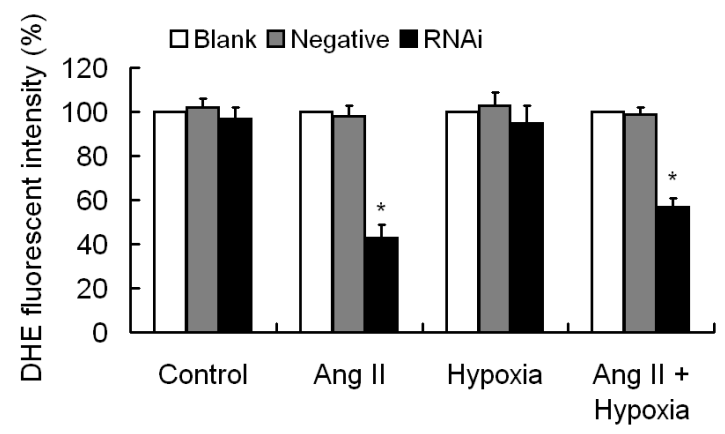

Figure 7 Effects of inhibition of PKC $\varepsilon$ on ROS in cardiomyocytes under hypoxia and/or Ang II stimulation. RNA interference by lentivirus infection decreased PKC $\varepsilon$ protein expression. No virus was used as the blank control group, and empty virus was used as the negative control group. (A) Representative images of cardiomyocytes in each group stained by DHE under fluorescence microscope. Scale bar: 100 $\mu \mathrm{m}$. (B) Quantitative fluorescence intensity of DHE staining showed that intracellular ROS production in the siRNA group was significantly reduced under Ang II stimulation alone or mixed hypoxia treatment, but there was no significant difference under hypoxia alone. $\mathrm{n}=5$, ${ }^{*} \mathrm{P}<0.05$, vs. the blank control group or the negative control group. 
A
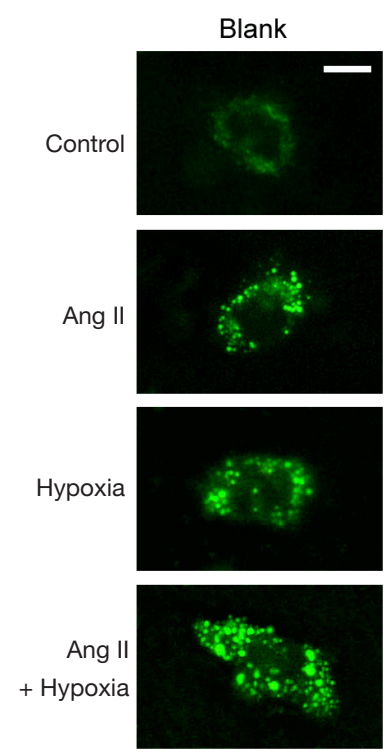

B
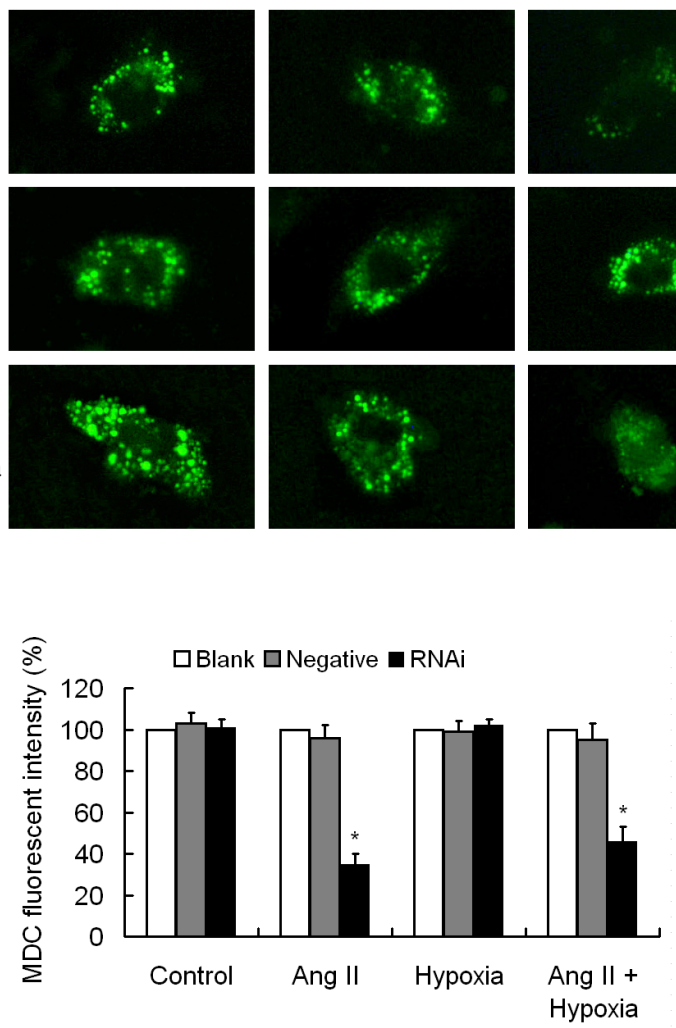

C
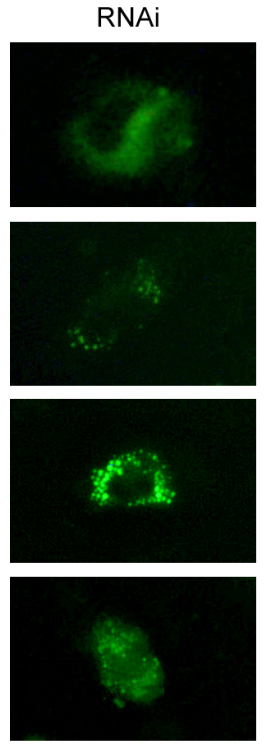

D

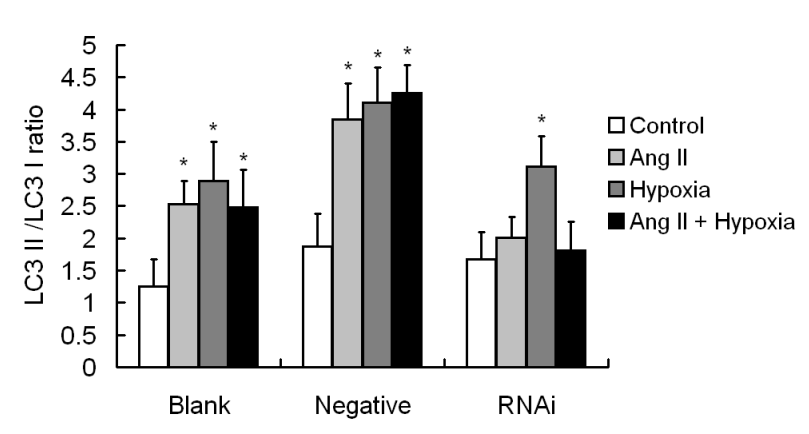

Figure 8 Effects of inhibition of PKC $\varepsilon$ on autophagy in cardiomyocytes under hypoxia and/or Ang II stimulation. RNA interference using lentivirus infection decreased PKC $\varepsilon$ expression. No virus was used as the blank control group, and empty virus was used as the negative control group. (A) Representative images of cardiomyocytes in each group stained by MDC under fluorescence microscopy. Scale bar: $10 \mu \mathrm{m}$. (B) Quantified fluorescence intensity of MDC staining showed that the autophagic activity of the cells in the siRNA group was significantly reduced under Ang II stimulation or mixed hypoxia condition, while the autophagic activity was not significantly different in the control group under the single hypoxia condition. $\mathrm{n}=5,{ }^{*} \mathrm{P}<0.05$, vs. the blank control group or the negative control group. (C) Representative images of LC3 protein expression and GAPDH as the loading control. (D) Quantitative comparison of LC3 II/LC3 I ratio confirmed that the autophagic activity of the cardiomyocytes in the siRNA group was significantly reduced under Ang II stimulation or mixed hypoxia condition, but was not significantly different from that of the control group under the hypoxia alone. $\mathrm{n}=5$, ${ }^{*} \mathrm{P}<0.05$, vs. the blank control group or the negative control group.

ROS, and autophagy. Specially, we focused on the important intermediate regulatory molecules that involving Ang II inducing autophagy.

We explored the relationship between intracellular ROS production and autophagy, and we found that the ROS content in cardiomyocytes was increased, accompanied by an increase in autophagic activity, which showed that inhibiting ROS production significantly reduced the autophagic activity in cardiomyocytes. It has been reported that ROS can damage large molecular proteins and organelles in cells through oxidation, thus inducing autophagy $(37,38)$. It is well known that NADPH oxidase 
(NOX) and Dual oxidase (DUOX), as well as mitochondria, are the major sources of ROS (39-41). Changes in mitochondrial membrane permeability caused by oxidative damage can itself induce autophagy. In starvation-induced autophagy experiments, researchers found that intracellular ROS positive regions co-localized with mitochondria (41). Autophagy is an important protective cellular mechanism against oxidative stress. It can remove ROS by phagocytosis of damaged mitochondria (19). Increasing evidence suggests that overproduced ROS regulate autophagy. ROS are important signaling molecules that regulate many signal transduction pathways and play critical roles in autophagy, and low intracellular concentration of ROS is an important signaling marker of autophagic cell death (42).

PKC $\varepsilon$ and PKC $\delta$ are the two major PKC subtypes involved in hypoxic and ischemia injury in the myocardium (22). Studies with specific inhibitory peptides of different PKC subtypes and transgenic mice have reported the roles of PKC $\varepsilon$ and PKC $\delta$ in myocardial ischemia/reperfusion injury. PKC $\varepsilon$ and PKC $\delta$ act in an opposing manner that the former is harmful and the latter is protective (43). This view was supported by a living model of acute myocardial infarction (AMI) in large animals $(44,45)$. In many cell or animal models, Ang II can exert various physiological or pathological effects by activating PKC (46-50). White et al. found that Ang II inhibited the NADPH oxidase pathway by activating the $\mathrm{Na}^{+}-\mathrm{K}^{+}$pump, which is a $\mathrm{PKC} \varepsilon$ dependent signal transduction pathway (51). Our results showed that the protein expression levels of PKC $\varepsilon$ and PKC $\delta$ in cardiomyocytes were increased under hypoxia or Ang II stimulation. Therefore, we further investigated the roles of these two proteins in cardiomyocyte autophagy.

Using the PKC $\delta$-specific inhibitor, Rottlerin, we observed the changes in ROS content and autophagic activity in cardiomyocytes. The ROS content and autophagic activity were significantly reduced under hypoxia and Ang II stimulation, while Ang II stimulation alone had no effect on ROS content and autophagy. This suggested that the hypoxia-induced autophagy of cardiomyocytes may function via $\mathrm{PKC} \delta$, but $\mathrm{PKC} \delta$ did not regulate autophagy induced by Ang II. It has been reported that the increased activity of PKC $\delta$ is the protective response of cells against oxidative stress (52), especially in cardiomyocytes suffering from some chronic hypoxia $(53,54)$. Some researchers proposed that under acute hypoxia, PKC $\delta$ will induce Bcl-2 phosphorylation and dissociate the Bcl-2/Beclin 1 protein complex mediated by c-Jun $\mathrm{N}$-terminal protein kinase1 (JNK1), thus inducing autophagy and playing a protective role. During chronic hypoxia, PKC $\delta$ is cleaved by apoptosis-related protease Caspase- 3 into fragments of PKC $\delta$-CF, which catalyzes its own proteolytic activity and induces apoptosis (27). According to our results, there may be a PKC $\delta / \mathrm{NADPH}$ oxidase/ROS dependent pathway involved in hypoxia-induced autophagy in cardiomyocytes. This pathway may interact with other signaling pathways by forming networks, but the exact mechanism needs to be further explored.

Our preliminary experimental results suggested that PKC $\varepsilon$ may play an important role in Ang II-induced autophagy. However, the underlying mechanism is still unknown. Therefore, we constructed an RNA interference lentiviral vector for PKC $\varepsilon$, which we used to decrease PKC $\varepsilon$ protein expression in cardiomyocytes. We then observed the changes in ROS content and autophagic activity in cardiomyocytes under various stress conditions. We found that knockdown of PKC $\varepsilon$ decreased ROS content and autophagic activity in cardiomyocytes under Ang II stimulation or combined stimulation of Ang II and hypoxia, but had no effect under hypoxia alone. This suggested that PKC $\varepsilon$ was an important mediating molecule for autophagy induced by Ang II. A recent study showed that chronic Ang II stimulation can activate $\mathrm{PKC} \varepsilon$ via phosphorylation of AT1 receptors in a time and dose-dependent manner, and that activated PKC $\varepsilon$ can induce cardiac hypertrophy through extracellular signal-regulated kinase 5 (ERK5) (55). Moreover, it has been reported that Ang II can inhibit the sarcolemmal $\mathrm{Na}^{+}-\mathrm{K}^{+}$pump in cardiomyocytes through PKC $\varepsilon / \mathrm{NADPH}$ oxidase pathway (51). A recent study showed that PKC $\varepsilon$ mediates the inhibitory action of Ang II on the slowly activating delayed rectifier $\mathrm{K}+$ current (IKs) in myocardium (56). Nevertheless, autophagy induced by PKC $\varepsilon$ is rarely reported.

\section{Conclusions}

In conclusion, our results identified that autophagy was enhanced in primary cultured cardiomyocytes under hypoxia and/or Ang II stimulation, and indicated that PKC $\delta$ and PKC $\varepsilon$ are key regulatory factors in this process. Importantly, we are the first to propose a role of PKC $\varepsilon$ in Ang II-induced autophagy. There is a complex environment of both hypoxia and Ang II accumulation in the heart following severe burn. Therefore, a single-factor regulation of autophagy is difficult to achieve the purposes of prevention and treatment. However, it will provide a more complete understanding of autophagy and provide insight 
into reasonable therapeutic targets to perform further studies to investigate the roles of AT1 and AT2 in Ang IIinduced autophagy pathway and how NADPH oxidase is activated by $\mathrm{PKC} \varepsilon$ to produce ROS.

\section{Acknowledgments}

Funding: This work was supported by a grant from the Key Project of National Natural Science Foundation of China (NSFC) (No. 81430042) and the Military Medical Science and Technology Youth Training Program (No. 20QNPY074).

\section{Footnote}

Reporting Checklist: The authors have completed the ARRIVE reporting checklist. Available at http://dx.doi. org/10.21037/cdt-20-883

Data Sharing Statement: Available at http://dx.doi. org/10.21037/cdt-20-883

Conflicts of Interest: All authors have completed the ICMJE uniform disclosure form (available at http://dx.doi. org/10.21037/cdt-20-883). The authors have no conflicts of interest to declare.

Ethical Statement: The authors are accountable for all aspects of the work in ensuring that questions related to the accuracy or integrity of any part of the work are appropriately investigated and resolved. The protocols concerning animal experiments were reviewed and approved by the Animal Experimental Ethics Committee of the Third Military Medical University, Chongqing, China (SYXKCQ-20070002), in compliance with Chinese national or institutional guidelines for the care and use of animals.

Open Access Statement: This is an Open Access article distributed in accordance with the Creative Commons Attribution-NonCommercial-NoDerivs 4.0 International License (CC BY-NC-ND 4.0), which permits the noncommercial replication and distribution of the article with the strict proviso that no changes or edits are made and the original work is properly cited (including links to both the formal publication through the relevant DOI and the license). See: https://creativecommons.org/licenses/by-nc-nd/4.0/.

\section{References}

1. Levine B, Kroemer G. Autophagy in the pathogenesis of disease. Cell 2008;132:27-42.

2. Klionsky DJ, Emr SD. Autophagy as a regulated pathway of cellular degradation. Science 2000;290:1717-21.

3. Kabeya Y, Mizushima N, Ueno T, et al. LC3, a mammalian homologue of yeast Apg8p, is localized in autophagosome membranes after processing. EMBO J 2000;19:5720-8.

4. Shi B, Ma M, Zheng Y, et al. mTOR and Beclin1: Two key autophagy-related molecules and their roles in myocardial ischemia/reperfusion injury. J Cell Physiol 2019;234:12562-8.

5. Yan L, Vatner DE, Kim SJ, et al. Autophagy in chronically ischemic myocardium. Proc Natl Acad Sci U S A 2005;102:13807-12.

6. Hamacher-Brady A, Brady NR, Gottlieb RA. Enhancing macroautophagy protects against ischemia/ reperfusion injury in cardiac myocytes. J Biol Chem 2006;281:29776-87.

7. Aki T, Yamaguchi K, Fujimiya T, et al. Phosphoinositide 3-kinase accelerates autophagic cell death during glucose deprivation in the rat cardiomyocyte-derived cell line H9c2. Oncogene 2003;22:8529-35.

8. Valentim L, Laurence KM, Townsend PA, et al. Urocortin inhibits Beclin1-mediated autophagic cell death in cardiac myocytes exposed to ischaemia/reperfusion injury. J Mol Cell Cardiol 2006;40:846-52.

9. Matsui Y, Takagi H, Qu X, et al. Distinct roles of autophagy in the heart during ischemia and reperfusion: roles of AMP-activated protein kinase and Beclin 1 in mediating autophagy. Circ Res 2007;100:914-22.

10. Yin ZG, Huang YS, Li BX. Changes and relations between heart function and organ blood flow in rats at early stage of severe burn. Zhonghua Shao Shang Za Zhi 2010;26:10-3.

11. Yang J, Yang $Z$, Chen F. Changes in cardiac reninangiotensin system after severe burn injury in rats. Zhonghua Zheng Xing Shao Shang Wai Ke Za Zhi 1999;15:102-4.

12. Paul M, Poyan Mehr A, et al. Physiology of local reninangiotensin systems. Physiol Rev 2006;86:747-803.

13. Mackins CJ, Kano S, Seyedi N, et al. Cardiac mast cellderived renin promotes local angiotensin formation, norepinephrine release, and arrhythmias in ischemia/ reperfusion. J Clin Invest 2006;116:1063-70. 
14. Peters H, Unger T. Mast cells and the power of local RAS activation. Nephrol Dial Transplant 2007;22:40-2.

15. Porrello ER, Delbridge LM. Cardiomyocyte autophagy is regulated by angiotensin II type 1 and type 2 receptors. Autophagy 2009;5:1215-6.

16. Porrello ER, D'Amore A, Curl CL, et al. Angiotensin II type 2 receptor antagonizes angiotensin II type 1 receptormediated cardiomyocyte autophagy. Hypertension 2009;53:1032-40.

17. Steckelings UM, Unger T. Angiotensin receptors and autophagy: live and let die. Hypertension 2009;53:898-9.

18. Garrido AM, Griendling KK. NADPH oxidases and angiotensin II receptor signaling. Mol Cell Endocrinol 2009;302:148-58.

19. Scherz-Shouval R, Elazar Z. ROS, mitochondria and the regulation of autophagy. Trends Cell Biol 2007;17:422-7.

20. Nishizuka Y. Intracellular signaling by hydrolysis of phospholipids and activation of protein kinase C. Science 1992;258:607-14.

21. Nishizuka Y. The role of protein kinase $C$ in cell surface signal transduction and tumour promotion. Nature 1984;308:693-8.

22. Budas GR, Churchill EN, Mochly-Rosen D. Cardioprotective mechanisms of PKC isozyme-selective activators and inhibitors in the treatment of ischemiareperfusion injury. Pharmacol Res 2007;55:523-36.

23. Duquesnes N, Lezoualc'h F, Crozatier B. PKC- $\delta$ and PKC- $\varepsilon$ : foes of the same family or strangers? J Mol Cell Cardiol 2011;51:665-73.

24. Toton E, Romaniuk A, Budzianowski J, et al. Zapotin (5,6,2',6'-tetramethoxyflavone) Modulates the Crosstalk Between Autophagy and Apoptosis Pathways in Cancer Cells with Overexpressed Constitutively Active PKC. Nutr Cancer2016;68:290-304.

25. So KY, Oh SH. Cadmium-induced heme-oxygenase-1 expression plays dual roles in autophagy and apoptosis and is regulated by both $\mathrm{PKC}-\delta$ and $\mathrm{PKB} / \mathrm{Akt}$ activation in NRK52E kidney cells. Toxicology 2016;370:49-59.

26. Zhang $\mathrm{Y}, \mathrm{Wu} \mathrm{Y}$, Tashiro S, et al. Involvement of PKC signal pathways in oridonin-induced autophagy in HeLa cells: a protective mechanism against apoptosis. Biochem Biophys Res Commun 2009;378:273-8.

27. Chen JL, Lin HH, Kim KJ, et al. PKC $\delta$ signaling: a dual role in regulating hypoxic stress-induced autophagy and apoptosis. Autophagy 2009;5:244-6.

28. Song KS, Kim JS, Yun EJ, et al. Rottlerin induces autophagy and apoptotic cell death through a PKC- $\delta$ independent pathway in HT1080 human fibrosarcoma cells: the protective role of autophagy in apoptosis. Autophagy 2008;4:650-8.

29. Ozpolat B, Akar U, Mehta K, et al. PKC $\delta$ and tissue transglutaminase are novel inhibitors of autophagy in pancreatic cancer cells. Autophagy 2007;3:480-3.

30. Tsai $\mathrm{WH}, \mathrm{Wu} \mathrm{CH}, \mathrm{Yu} \mathrm{HJ}$, et al. 1-Theanine inhibits proinflammatory PKC/ERK/ICAM-1/IL-33 signaling, apoptosis, and autophagy formation in substance P-induced hyperactive bladder in rats. Neurourol Urodyn 2017;36:297-307.

31. Xiao R, Teng M, Zhang Q, et al. Myocardial autophagy after severe burn in rats. PLoS One 2012;7:e39488.

32. Wu JB, Zhou Y, Liang CL, et al. Cyclovirobuxinum D alleviates cardiac hypertrophy in hyperthyroid rats by preventing apoptosis of cardiac cells and inhibiting the p38 mitogen-activated protein kinase signaling pathway. Chin J Integr Med 2017;23:770-8.

33. Peshavariya HM, Dusting GJ, Selemidis S. Analysis of dihydroethidium fluorescence for the detection of intracellular and extracellular superoxide produced by NADPH oxidase. Free Radic Res 2007;41:699-712.

34. Vázquez CL, Colombo MI. Assays to assess autophagy induction and fusion of autophagic vacuoles with a degradative compartment, using monodansylcadaverine (MDC) and DQ-BSA. Methods Enzymol 2009;452:85-95.

35. Klionsky DJ, Abdelmohsen K, Abe A, et al. Guidelines for the use and interpretation of assays for monitoring autophagy (3rd edition). Autophagy 2016;12:1-222.

36. Zhao D, Gao Y, Wang W, et al. PKD deletion promotes autophagy and inhibits hypertrophy in cardiomyocyte. Exp Cell Res 2020;386:111742.

37. Bai YD, Yang YR, Mu XP, et al. Hydrogen Sulfide Alleviates Acute Myocardial Ischemia Injury by Modulating Autophagy and Inflammation Response under Oxidative Stress. Oxid Med Cell Longev 2018;2018:3402809.

38. Kiffin R, Bandyopadhyay U, Cuervo AM. Oxidative stress and autophagy. Antioxid Redox Signal 2006;8:152-62.

39. Bedard K, Krause KH. The NOX family of ROSgenerating NADPH oxidases: physiology and pathophysiology. Physiol Rev 2007;87:245-313.

40. Amanso AM, Griendling KK. Differential roles of NADPH oxidases in vascular physiology and pathophysiology. Front Biosci (Schol Ed) 2012;4:1044-64.

41. Adam-Vizi V, Chinopoulos C. Bioenergetics and the formation of mitochondrial reactive oxygen species. Trends Pharmacol Sci 2006;27:639-45.

42. Xu Y, Kim SO, Li Y, et al. Autophagy contributes to caspase-independent macrophage cell death. J Biol Chem 
2006;281:19179-87.

43. Rong B, Xie F, Sun T, et al. Nitric oxide, PKC- $\varepsilon$, and connexin43 are crucial for ischemic preconditioninginduced chemical gap junction uncoupling. Oncotarget 2016;7:69243-55.

44. Wang Q, Zhang X, Ding Q, et al. Limb remote postconditioning alleviates cerebral reperfusion injury through reactive oxygen species-mediated inhibition of delta protein kinase $\mathrm{C}$ in rats. Anesth Analg 2011;113:1180-7.

45. Inagaki K, Begley R, Ikeno F, et al. Cardioprotection by $\varepsilon$-protein kinase $\mathrm{C}$ activation from ischemia: continuous delivery and antiarrhythmic effect of an $\varepsilon$-protein kinase C-activating peptide. Circulation 2005;111:44-50.

46. Huang A, Yan C, Suematsu N, et al. Impaired flowinduced dilation of coronary arterioles of dogs fed a lowsalt diet: roles of ANG II, PKC, and NAD(P)H oxidase. Am J Physiol Heart Circ Physiol 2010;299:H1476-83.

47. Perry C, Blaine J, Le H, et al. PMA- and ANG II-induced $\mathrm{PKC}$ regulation of the renal $\mathrm{Na}+\mathrm{HCO} 3$ - cotransporter (hkNBCe1). Am J Physiol Renal Physiol 2006;290:F417-27.

48. Zhang Z, Rhinehart K, Kwon W, et al. ANG II signaling in vasa recta pericytes by $\mathrm{PKC}$ and reactive oxygen species. Am J Physiol Heart Circ Physiol 2004;287:H773-81.

49. Pham H, Chong B, Vincenti R, et al. Ang II and EGF synergistically induce COX-2 expression via CREB in intestinal epithelial cells. J Cell Physiol 2008;214:96-109.

50. Abbas M, Jesel L, Auger C, et al. Endothelial Microparticles From Acute Coronary Syndrome Patients
Induce Premature Coronary Artery Endothelial Cell Aging and Thrombogenicity: Role of the Ang II/AT1 Receptor/ NADPH Oxidase-Mediated Activation of MAPKs and PI3-Kinase Pathways. Circulation 2017;135:280-96.

51. White CN, Figtree GA, Liu CC, et al. Angiotensin II inhibits the $\mathrm{Na}+\mathrm{K}+$ pump via $\mathrm{PKC}$-dependent activation of NADPH oxidase. Am J Physiol Cell Physiol 2009;296:C693-700.

52. Kim MJ, Moon CH, Kim MY, et al. Role of PKC- $\delta$ during hypoxia in heart-derived H9c2 cells. Jpn J Physiol 2004;54:405-14.

53. Cataldi A, Zingariello M, Rapino M, et al. Effect of hypoxia and aging on PKC $\delta$-mediated SC-35 phosphorylation in rat myocardial tissue. Anat Rec (Hoboken) 2009;292:1135-42.

54. Kolár F, Jezková J, Balková P, et al. Role of oxidative stress in PKC- $\delta$ upregulation and cardioprotection induced by chronic intermittent hypoxia. Am J Physiol Heart Circ Physiol 2007;292:H224-30.

55. Zhao Z, Wang W, Geng J, et al. Protein kinase C $\varepsilon$-dependent extracellular signal-regulated kinase 5 phosphorylation and nuclear translocation involved in cardiomyocyte hypertrophy with angiotensin II stimulation. J Cell Biochem 2010;109:653-62 .

56. Gou X, Wang W, Zou S, et al. Protein kinase C epsilon mediates the inhibition of angiotensin II on the slowly activating delayed-rectifier potassium current through channel phosphorylation. J Mol Cell Cardiol 2018;116:165-74.
Cite this article as: Xiao R, Zhao HC, Yan TT, Zhang Q, Huang YS. Angiotensin II and hypoxia induce autophagy in cardiomyocytes via activating specific protein kinase C subtypes. Cardiovasc Diagn Ther 2021;11(3):744-759. doi: 10.21037/cdt20-883 